Article

\title{
Consumers' Willingness to Pay for Foods with Traceability Information: Ex-Ante Quality Assurance or Ex-Post Traceability?
}

\author{
Bo Hou ${ }^{1}$, Linhai $\mathrm{Wu}^{2, *}$, Xiujuan Chen ${ }^{2}$, Dian Zhu ${ }^{3}$, Ruiyao Ying ${ }^{4}$ and Fu-Sheng Tsai ${ }^{5,6,7}$ \\ 1 School of Philosophy and Public Administration, Jiangsu Normal University, Xuzhou 221116, China; \\ houbo0451@126.com \\ 2 Food Safety Research Base of Jiangsu Province (School of Business), Jiangnan University, Synergetic \\ Innovation Center of Food Safety and Nutrition, Wuxi 214122, China; xjchen@jiangnan.edu.cn \\ 3 School of Dongwu Business, Soochow University, Suzhou 215021, China; 15150157673@139.com \\ 4 College of Economic and Management, Nanjing Agricultural University, Nanjing 210095, China; \\ yry@njau.edu.cn \\ 5 Department of Business Administration, Cheng Shiu University, Kaohsiung 83347, Taiwan; \\ tsaifs@gcloud.csu.edu.tw \\ 6 Center for Environmental Toxin and Emerging-Contaminant Research, Cheng Shiu University, \\ Kaohsiung 83347, Taiwan \\ 7 Super Micro Mass Research and Technology Center, Cheng Shiu University, Kaohsiung 83347, Taiwan \\ * Correspondence: wlh6799@jiangnan.edu.cn
}

Received: 21 January 2019; Accepted: 4 March 2019; Published: 9 March 2019

\begin{abstract}
In this study, traceability in pork profile information with ex-ante quality assurance and ex-post traceability are constructed. Consumers' willingness to pay (WTP) for traceability information is investigated in Wuxi, China, by combining the Multiple Price Lists method and the Becker-DeGrootMarschak (BDM) experimental auction. The main factors affecting consumers' WTP are also analyzed using a Tobit model. The results demonstrate that consumers have higher WTP for ex-ante quality assurance than for ex-post traceability. The highest WTP is for the ex-ante quality assurance attribute of pork quality inspection. Consumers' WTP for traceability information is influenced by their individual characteristics, including age, education and income, as well as their concern and satisfaction about food safety and confidence in food safety labeling. The contribution of this paper is that it improves the meaning of traceable food information attributes and measures the significance of attributes to consumers. Furthermore, this paper introduces a Becker-DeGroot-Marschak experimental auction method which amends the measurement deviation of hypothetical experiments.
\end{abstract}

Keywords: willingness to pay; traceability in pork information; ex-ante quality assurance; ex-post traceability; Becker-DeGroot-Marschak experimental auction; multiple price list

\section{Introduction}

Consumers today must pay close attention to food safety, with an urgent need for high-quality food with information transparency and safety assurances [1]. Food traceability systems can reduce information asymmetry, implement safety governance across geographical boundaries and help increase consumer faith in food safety to achieve sustainable agricultural development [2,3]. Food traceability systems have been widely implemented in developed countries and have played an increasingly important role in food safety insurance [4].

However, less is known about consumers' detailed reactions to differentiated information provided by such traceability systems generated at different stages of food production/supply. 
Regulation (EC) No. 178/2002 implemented by the European Union suggestively defines the content of food traceability information, requiring that food traceability information should cover as many as possible the processes in a food supply chain and defines the information attributes that should be included for each process. Hobbs et al. [5] indicated that a complete food traceability system should possess the basic functions of both ex-ante quality assurance and ex-post traceability (Ex-ante quality assurance enables consumers to confirm food safety and quality prior to purchase via credence attribute labels. Ex-post traceability allows for timely recall with complete traceability information along the food supply chain in the event of food safety problems and establishes accountability for such problems.). In such cases, complete food traceability systems do not only contain simple information [5]. Although the development of modern information technology has provided effective improvement for the breadth, depth and accuracy of food traceability systems, Cadillac-type traceable food (This term comes from the reference [5] Cadillac-type traceable food refers to all kinds of foods containing detailed traceable information with advanced technology.) does not have the largest market demand due to limited consumer income [5,6]. This implies that the effectiveness of a traceable food system relies not only on adopting technology but also on the support and recognition of consumers. Hence, research on consumer willingness to pay (WTP) should be more delicate by looking into consumers' perception and reaction towards different information (i.e., here, ex-ante quality assurance and ex-post traceability) benefits provided by traceability systems.

We chose China to conduct a study that might fill the above mentioned gap in the literature. The reason for choosing China as an interesting context is based on the fact that its existing traceable food pilot systems only provide incomplete ex-post traceability [7]. Precisely because of the lack of ex-ante quality assurance, current traceability in pork in the Chinese food markets cannot effectively solve market failure resulting from information asymmetry [8], which has led to a lack of market demand [7]. In such a context, the utility of information from food traceability systems is even less clear, thus demanding a scientific study.

\section{Literature Review}

The theory of Lancaster [9] suggests that consumer utility is given by attributes of the product rather than the product itself. Consumer utility is derived from an information attribute [10]. Studies have shown that traceability in food information can provide ex-ante quality assurance if traceability information attributes are incorporated into the food traceability systems with other attributes, such as animal welfare, origin certification, quality inspection and environmental impact [11]. Wu et al. [12] indicated that ex-ante quality assurance was more effective in eliminating information asymmetry than ex-post traceability. Note that, however, food quality is not equal to food safety in concept. As food safety incidents continue to occur on a global scale, consumers expect that they will be able to confirm food quality and safety when making purchasing decisions, thus preferring food with information traceability, quality assurance and certification information [13-16]. However, other studies have indicated that simple information, such as appearance, is an important factor that influences consumer choice $[17,18]$. Therefore, consumers have varying degrees of preference for traceability information, information certification, quality and safety assurance, appearance and color. These information attributes are distributed in different processes of the supply chain system of traceable food profiles, reflecting the quality and safety of food from different perspectives and together constituting a food traceability system with ex-ante quality assurance and ex-post traceability. This could especially be true in countries where traceability is not mandatory.

Numerous studies have investigated consumer preferences and WTP for traceability information in different countries using hypothetical experiments. Despite some differences, the overall conclusion has been that consumers are willing to pay a premium for food with traceability information [19-22]. At the same time, non-hypothetical experiments have also shown that Chinese consumers have a WTP for traceability in pork with different levels of information attributes. These previous studies 
demonstrate a consistent preference ranking for the information attributes of traceable food profiles, despite differences in consumers' WTP under different experimental mechanisms [23,24].

Existing literature provides a useful reference for this study. However, there are still some remaining deficiencies. First, there are rich meanings for the information attributes of traceable food profiles, however the literature rarely distinguishes the significance of different meanings on the participants of food with information traceability. As mentioned above, the food traceability system should have both ex-ante quality assurance function and ex-post traceability function, however the majority of earlier research made no strict distinction between the two kinds of attributes of food with information traceability. In fact, the ex-ante quality assurance function and ex-post traceability function of food with information traceability are different in the way of preventing food safety risks $[11,24]$ and there are also differences in consumer preferences between the two kinds of attributes. Therefore, the information attributes of the two functions cannot be completely replaced with each other. Second, due to differences in development stages and consumer culture, the information attributes of traceable food profiles established in earlier studies are not suitable for China. For example, consumers in developed countries are generally concerned about animal welfare, which, at least for now, is not a widespread concern among Chinese consumers. Third, most earlier research involved hypothetical experiments. However, the validity and reliability of such experiments have been questioned due to their very hypothetical nature and the fact that they lack incentive and restraint mechanisms, which often leads to strategic errors because participants in experiments exaggerate their willingness to pay [25]. Therefore, this study attempted to establish a relatively complete system of pork attributes traceability with basic functions of ex-ante quality assurance and ex-post traceability based on the major safety risks in China's pork supply chain system and to investigate consumers' WTP for information attributes of pork information traceability using multiple price list (MPL) and Becker-DeGroot-Marschak (BDM) experimental auction to identify a traceable pork profile system that better meets actual market demand in China.

\section{Methodology}

\subsection{Selection of Food Type}

China has a large economy of pork consumption and production; in 2015, China's pork production and consumption amounted to 54.87 million tons and 55.47 million tons, respectively, accounting for $49 \%$ and $52 \%$ of world pork production and consumption, respectively. Pork is one of the earliest traceable foods to appear on the Chinese market. Therefore, we investigated pork information traceability in this study. Taking into account the different consumer preferences for different parts of traceable pork profiles of the same variety, pork hindquarters were selected to exclude interference from non-essential elements when investigating consumers' WTP.

\subsection{Information Attributes}

Chain-and-internal information is the primary tool used to identify, preserve and deliver product quality and difference. For traceable food profiles, information also has the fundamental function of delivering traceability and security status [26]. The use of information enables companies to pass product quality signals and other property signals with added value potential to consumers. For consumers, information allows them to identify specific quality characteristics or product attributes that they prefer and are willing to pay for.

Hobbs [5] summarized the necessary information for establishing a food traceability system into ex-ante quality assurance and ex-post traceability. Information attributes with ex-post traceability capabilities facilitate the recall of risky food and the identification of sources of problems and responsible parties after a food safety incident. The degree of such tracing-back effect is closely related to whether the setting of traceable food information attributes completely covers key risk points in the food supply chain system. At present, China's pork quality and safety risks exist in all aspects of 
the breeding, slaughtering, transportation and sales of the entire supply chain system [27], as shown in Figure 1 . The traceability system that only contains the attributes of a certain part in the whole supply chain cannot implement the function of ex-post traceability. To respond to such insufficiency, we tried to set up information attributes that could cover the major processes of the entire pork supply chain. Among these information attributes, Type III includes basic information about enterprise in the pork supply chain. Type IV information includes the same contents as type III and also critical internal safety records such as the source of feed, veterinary drug use and inspection.

\section{Major processes of} the pork supply chain

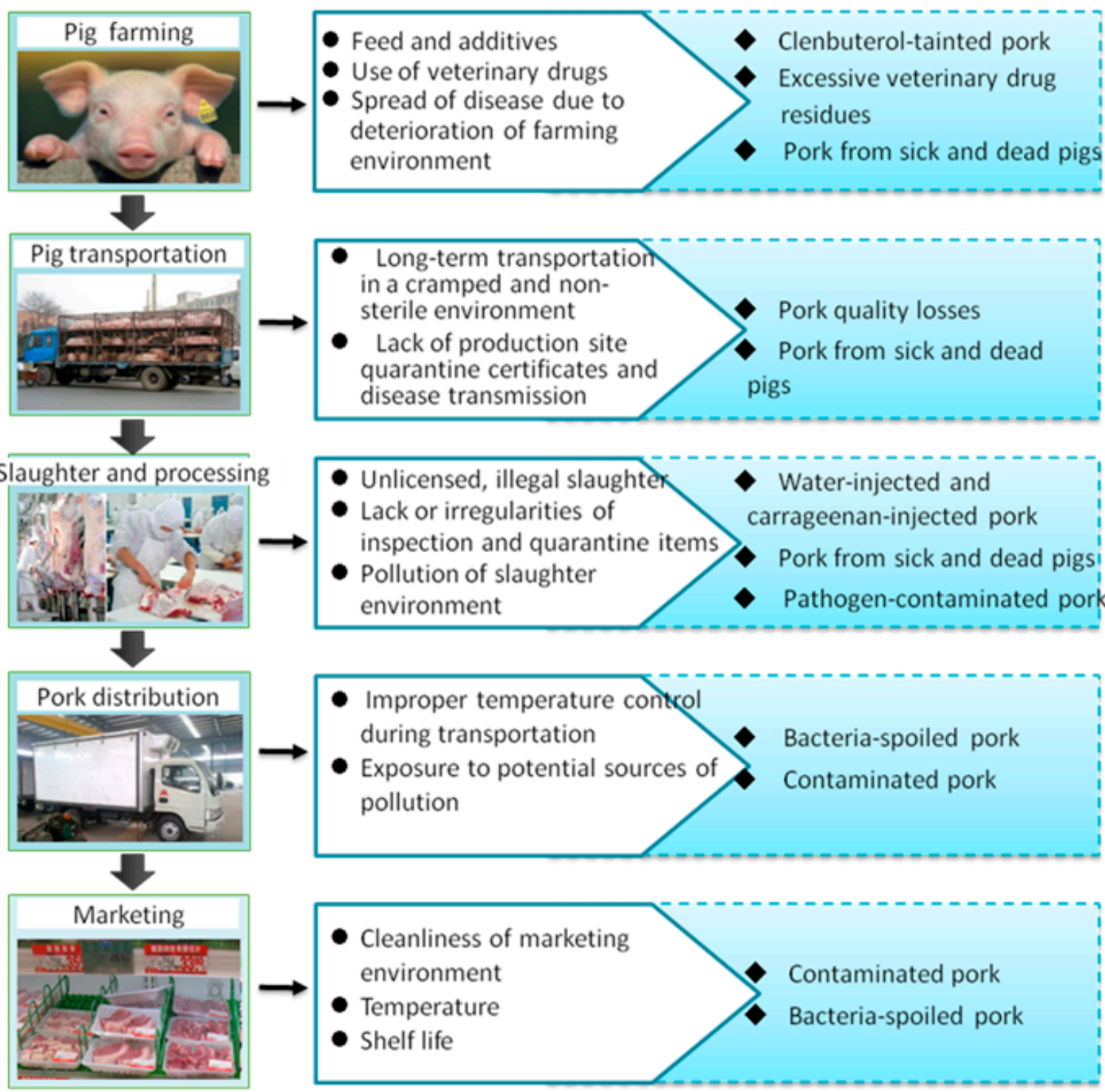

Figure 1. Major processes of the pork supply chain and the corresponding safety risks.

Information attributes with ex-ante quality assurance capabilities provide consumers with trust in pork quality safety and are mainly translated into search attributes that are easy for consumers to identify; this not only reduces the cost to the consumer of searching for quality information but also has an early warning effect on food safety consumption. At present, China's routine pork inspection and quarantine measures do not require the measurement of physical, chemical or microbiological indicators. Therefore, pork quality inspection was included as an attribute, represented by a label issued by a third party, to provide consumers with the pork information shown in Table 1. According to 
the research findings of Reid, O'Donnell and Downey [28] and Sterling et al. [3], quality management system certification was also included as an attribute, represented by a certification mark issued by a third party. This attribute provides consumers with information about pork quality assurance measures and production process controllability of the pork slaughter and processing enterprises.

Therefore, in this study, four different types of traceable pork profiles with different information attributes were investigated. Compared with regular pork, the respective information attributes included in the four types of traceable pork information were: (1) pork quality inspection (type I); (2) quality management system certification (type II); (3) supply chain traceability (type III); and (4) supply chain-and-internal traceability (type IV). Such categorization is based on practical knowledge from the government and industry practitioners, which might fit to the researched context best.

Table 1. Settings of information attributes.

\begin{tabular}{|c|c|c|c|}
\hline Function & Attribute & Type & Explanation Given to Participants \\
\hline \multirow{2}{*}{$\begin{array}{l}\text { Ex-ante quality } \\
\text { assurance }\end{array}$} & Pork quality inspection & $\begin{array}{l}\text { Type I } \\
\text { Labeling as acceptable }\end{array}$ & $\begin{array}{l}\text { Labeling products as acceptable after } \\
\text { testing of physical and chemical indicators, } \\
\text { such as pesticide and veterinary drug } \\
\text { residues and microbial indicators, such as } \\
\text { number of Escherichia coli, by a qualified } \\
\text { testing agency. }\end{array}$ \\
\hline & $\begin{array}{l}\text { Quality management } \\
\text { system } \\
\text { certification }\end{array}$ & $\begin{array}{l}\text { Type II } \\
\text { Labeling as certified }\end{array}$ & $\begin{array}{l}\text { Labeling slaughtering and processing } \\
\text { enterprises with a mark of quality } \\
\text { management system certification after } \\
\text { review of quality and safety management } \\
\text { capability by a qualified certification } \\
\text { agency. }\end{array}$ \\
\hline \multirow[b]{2}{*}{ Ex-post traceability } & Supply chain traceability & $\begin{array}{l}\text { Type III } \\
\text { Labeling with a } \\
\text { traceability barcode }\end{array}$ & $\begin{array}{l}\text { Scanning Type III barcode through a public } \\
\text { inquiry platform, consumers can obtain the } \\
\text { basic information about enterprise in the } \\
\text { pork supply chain }\end{array}$ \\
\hline & $\begin{array}{l}\text { Supply } \\
\text { chain-and-internal } \\
\text { traceability }\end{array}$ & $\begin{array}{l}\text { Type IV } \\
\text { Labeling with a } \\
\text { traceability barcode }\end{array}$ & $\begin{array}{l}\text { Scanning Type IV barcode through a public } \\
\text { inquiry platform, consumers can obtain } \\
\text { information about what type III has, as well } \\
\text { as critical internal safety records such as the } \\
\text { source of feed, veterinary drug use and } \\
\text { inspection }\end{array}$ \\
\hline
\end{tabular}

\subsection{Selection of Experimental Method}

As compared to non-hypothetical experiments (e.g., the random Nth price auctions, rear choice experiment, the BDM and MPL used here), hypothetical experiments (including choice experiment, conjoint analysis, contingent valuation methods, etc.) do not provide economic incentives to reveal true values and participants tend to falsely express their WTP [25,29-33]. Non-hypothetical experiments, such as experimental auctions, can achieve incentive compatibility by simulating the real market environment via actual payment, thereby overcoming hypothetical experimental bias [34].

The MPL is a one-on-one inductive method for experiment. In the MPL mechanism, participants are given a payment card with prices ordered from low to high and asked to indicate whether they are willing to buy a product at each price level. Then one price and one product was randomly drawn as binding and participants who had indicated that they would buy the drawn product at the drawn price did so. Therefore, their dominant strategy is to say 'yes' at all prices up to their WTP and thereafter 'no.' Thereby, revealing the interval containing their true WTP [22]. Each participant in the MPL experiment could start immediately on their arrival to the experiment site. As they do not need to wait, their willingness to participate would be higher and the selection bias could be controlled to a minimum level. Such a method is also beneficial for the randomization of participant selection. Besides, the MPL allows disclosure for true WTP ranges of consumers and could reach the real upper limit of such WTP [31]. However, the MPL requires the researchers to set the price ranges prior to the implementation of the experiment, which could cause the bias that consumers' WTP would be 
affected by the price range set in the preliminary stage. Furthermore, the MPL lacks market bidding procedures, which limits the motivation effect of an experiment [35,36].

On the other hand, the BDM auction experiment is a one-on-one valuation technique which inherently has the random merits for the MPL. However, unlike MPL, subjects in BDM are asked to directly indicate the highest price they would be WTP for food with a particular safety attribute which is then compared to a randomly drawn selling price [37]. Furthermore, BDM has a randomized price generator allowing opportunities for bidders to win at higher or lower prices (i.e., not only higher prices have higher winning opportunity). Additionally, BDM also ensures fairness in the opportunity of being chosen for different types of products, thus ensuring the non-hypothetical nature of experimental auction $[7,38]$. However, the implemented procedures in BDM lack an extra mechanism of price induction and cannot disclose true WTP ranges of consumers [39]. In summary, it is reasonable and advantageous to combine these two experimental approaches for an important topic such as is presented here in our study. For more details about application of the MPL and the BDM mechanism, please refer to Reference $[22,31,33]$

\subsection{Preparation and Procedure of Experimental Auction}

Before the start of the experiment, each participant was given an ID number, $0.5 \mathrm{~kg}$ of regular pork and 5.0 yuan in cash as an incentive to participate in the experiment. Participants were told that the price of regular pork was 14.0 yuan $/ 0.5 \mathrm{~kg}$ in the city where the experiment was carried out. Next, four types of traceable pork information for auction were shown to the participants (Participants were told that the four types of traceable pork were no different from regular pork in packaging, appearance, weight or any other visible features, except quality and safety risks.) and the experiment conductors explained the inspection and certification marks. Then, participants were shown how to obtain traceability information by the computer-based traceability code search system. This was to ensure that participants had full confidence in the authenticity of the items for auction, so as to minimize measurement error resulting from non-confidence. Subsequently, the experiment and questionnaire were explained to participants and then it was tested whether the participants understood the experimental rules. Only the participants who passed the test were allowed to enter the experimental session. To prevent sequence effects between items, the sequence of items for auction was randomized.

In the MPL format, participants are given a payment card with prices recorded from low to high and asked to indicate whether they are willing to buy a product at each price level [22]. First, we (the experiment conductors) asked the bidders to submit a bid, representing the maximum amount they were willing to pay for each type of pork with information attributes, which is recorded as the initial WTP price and named as "WTP." We then gradually added 0.3 yuan onto the initial price and asked the participants if they were still willing to accept the added price, until they expressed that they could not accept the price anymore. Thus, we gained the final WTP price from the participants (i.e., maximum WTP named as "WTP ${ }_{n}$ ").

Then, according to the BDM rules, we gained a random price generated from the computer's generator program (randomly extracted binding value was unknown by the bidders). We compared the bidder's maximum WTP and the randomly generated price from our computer. The bidders won the bid if his/her maximum WTP was larger than the computer-generated one; otherwise, their bids failed. After four rounds of bidding, the computer program randomly picked up one set of scores from the four rounds of bidding results. For that randomly chosen set of scores, if the bidder won the bidding, then we exchanged the corresponding type of safe pork and payed at a price that was randomly generated by the computer; otherwise, the bidder could not exchange for pork that had higher safety attributes and could only keep the previously given ordinary pork. See Figure 2 for a comprehensive overview. 


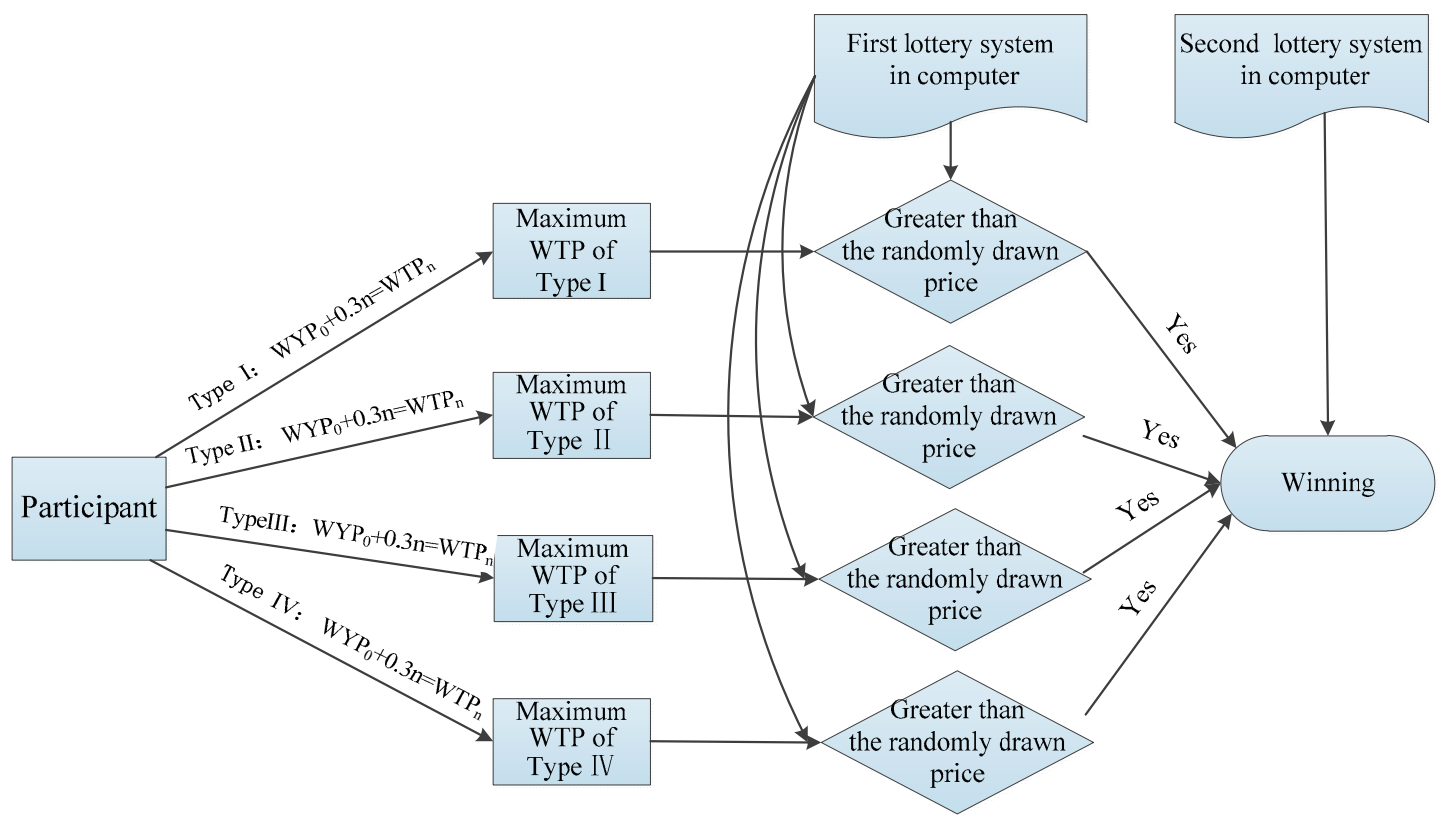

Figure 2. Experimental procedure combining multiple price list (MPL) and Becker-DeGroot-Marschak (BDM) auction method.

\subsection{Implementation of Experiment Auction}

The experiment was carried out in Wuxi City, Jiangsu Province, China. This site was selected as it is a pork profile traceability pilot city appointed by the Chinese Ministry of Commerce. The experiment was carried out in farmer's markets, supermarkets and pork shops where the Wuxi residents purchase pork. Based on a preliminary experiment, the third consumer that came into view was recruited to ensure sample randomness [40]. To ensure experiment quality, the rules of the MPL and BDM auction were fully explained to the participants before the experiment. At the end of the experiment, participants were instructed to complete a questionnaire regarding individual and family characteristics, knowledge about traceable pork information and purchase habits.

\subsection{Statistical Analysis of Participants}

A total of 270 pork consumers (hereinafter referred to as the participants) were recruited. Of these, 259 generated valid information for our further analysis. Women accounted for $53.3 \%$ of the participants; $35.5 \%$ of participants were aged $30-45$ years; $55.6 \%$ had a high school or lower education level; $57.2 \%$ had a monthly income of $3000-8000$ yuan; $62.6 \%$ had a family size of $3-4$; and married participants accounted for $84.2 \%$ of the sample. On average, the families of the participants purchased pork 2.5 times a week, consuming $1.8 \mathrm{~kg}$ of pork per week.

\subsection{Consumer Bids in the Experiment Auction}

The participants' bids for the four traceable pork information attributes are shown in Table 2. The results showed that the average level of maximum premium paid by the participants based on the BDM experiment auction method is higher than the average of the initial quotes. Therefore, it is effective to use the experimental auction method of the BDM mechanism to measure the maximum willingness of the participants to pay for pork with different types of information attributes. Compared with regular pork, the participants were willing to pay a premium of 3.9 and 3.2 yuan for pork quality inspection and quality management system certification, respectively. A premium of 2.9 yuan was offered for traceability to the major processes of the entire pork supply chain. A higher premium of 3.4 yuan was paid for traceability to the major processes of the entire pork supply chain plus critical internal safety information. Based on the average premiums paid, participants had a higher 
WTP for information attributes of ex-ante quality assurance. This coincides with the conclusions of Hobbs et al. [5], Verbeke and Ward [14] and Loureiro and Umberger [15]. As seen in Table 2, Mann-Whitney U-test analysis revealed significant differences in participants' bids for different types of information attributes.

Table 2. Participants' willingness to pay (WTP) for different information attributes ant the Mann-Whitney U test results.

\begin{tabular}{|c|c|c|c|c|c|c|c|c|}
\hline \multirow[b]{2}{*}{ Type } & \multicolumn{4}{|c|}{ Initial Quotations (Yuan) } & \multicolumn{4}{|c|}{ Final Quotations (Yuan) } \\
\hline & $\operatorname{Max}$ & Min & Mean & $\begin{array}{l}\text { Standard } \\
\text { Deviation }\end{array}$ & Max & Min & Mean & $\begin{array}{l}\text { Standard } \\
\text { Deviation }\end{array}$ \\
\hline Type I & 9.0 & 0.0 & 3.2 & 1.8 & 11.0 & 0.0 & 3.9 & 2.1 \\
\hline Type II & 8.0 & 0.0 & 2.5 & 1.7 & 9.0 & 0.0 & 3.2 & 1.9 \\
\hline Type III & 7.0 & 0.0 & 2.5 & 1.4 & 10.0 & 0.0 & 2.9 & 1.6 \\
\hline \multirow[t]{2}{*}{ Type IV } & 8.5 & 0.0 & 2.9 & 1.6 & 10.0 & 0.0 & 3.4 & 1.8 \\
\hline & & \multicolumn{2}{|c|}{ Group } & \multicolumn{2}{|c|}{ Mann-Whitney U } & Wilcoxon W & $\mathbf{Z}$ & Significance \\
\hline \multirow{6}{*}{$\begin{array}{l}\text { Mann-Whitney U } \\
\text { test results between } \\
\text { mean bids for } \\
\text { different } \\
\text { information } \\
\text { attributes }\end{array}$} & Pair 1 & \multicolumn{2}{|c|}{ Type I-Type II } & \multicolumn{2}{|c|}{$26,635.500$} & $60,305.500$ & -4.064 & 0.000 \\
\hline & Pair 2 & \multicolumn{2}{|c|}{ Type I-Type III } & \multicolumn{2}{|c|}{$24,791.000$} & $58,461.000$ & -5.150 & 0.000 \\
\hline & Pair 3 & \multicolumn{2}{|c|}{ Type I-Type IV } & \multicolumn{2}{|c|}{$28,961.500$} & $62,631.500$ & -2.693 & 0.007 \\
\hline & Pair 4 & \multicolumn{2}{|c|}{ Type II-Type III } & \multicolumn{2}{|c|}{$30,726.000$} & $64,396.000$ & -1.656 & 0.098 \\
\hline & Pair 5 & \multicolumn{2}{|c|}{ Type II-Type IV } & \multicolumn{2}{|c|}{$29,768.000$} & $63,438.000$ & -2.217 & 0.027 \\
\hline & Pair 6 & \multicolumn{2}{|c|}{ Type III-Type IV } & \multicolumn{2}{|c|}{$29,020.500$} & $62,690.500$ & -2.661 & 0.008 \\
\hline
\end{tabular}

\section{Research Framework, Econometric Model and Analysis Results}

\subsection{Model Selection and Variable Setting}

According to Lancaster's theoretical framework of consumer utility, $U_{n i}$ is the attribute utility obtained by the participant $n$ choosing type $i$ traceable pork information. Consumer utility $U_{n i}$ includes two parts, the deterministic term $V_{n i}$ and stochastic term $\varepsilon_{n i}$ as follows:

$$
U_{n i}=V_{n i}+\varepsilon_{n i}
$$

If the attribute utility obtained by the participant $n$ from traceable pork information of type $i$ is greater than that of ordinary pork, that is, if $U_{n i}>0$, consumers will pay a premium for the information attributes of traceable pork information for this type $i$. Participant's maximum willingness to pay for traceable pork information of type $i$ is denoted by $W T P_{n i}$. But if $U_{n i} \leq 0$, consumers will not pay premiums and $W T P_{n i}=0$.

Because the participant's WTP is a continuous variable of finite interval, this paper uses the Tobit model to study the influencing factors of consumers' willingness to pay for traceable pork information attributes. According to Xue, Mainville, You and Nayga Jr [18], $W T P_{n i}$ is affected by the individual characteristics of the participants, family characteristics, cognitive attitudes and other factors. Thus, we constructed our Tobit model as:

$$
\begin{aligned}
& W T P_{n i}=\alpha X_{n}+\varepsilon_{n} \\
& y_{i}=\left\{\begin{array}{cll}
W T P_{n i}, & \text { if } & W T P_{n i}>0 \\
\text { No Value, } & \text { if } & W T P_{n i}=0
\end{array}\right.
\end{aligned}
$$

where $X_{n}=\left[\begin{array}{llll}X_{n 11} \ldots X_{n 1 k} & & & \\ & X_{n 21} \ldots X_{n 2 k} & & \\ & & \ldots . . & \\ & & & X_{n i 1} \ldots X_{n i k}\end{array}\right]$ is a $i \times(i \times k)$-dimensional quasi-diagonal matrix and $X_{n i k}$ is the independent variable $k$ that affects the bid of participant $n$ in the experimental auction of type $i$ traceable pork information. In Equation (5), $\alpha$ is a parameter matrix to be estimated and $\varepsilon_{n}$ is a residual term, that is,

$$
\alpha=\left(\alpha_{11}, \alpha_{12}, \ldots \alpha_{1 k}, \alpha_{21}, \alpha_{22}, \ldots \alpha_{2 k}, \ldots \ldots \alpha_{n 1}, \alpha_{n 2}, \ldots \alpha_{n k}\right)^{\prime} \varepsilon_{n}=\left(\varepsilon_{n 1}, \varepsilon_{n 2}, \ldots \varepsilon_{n k}\right)^{\prime}
$$


As shown in Table 3, the final WTP price in the MPL offered by the participants for the four information attributes was defined as dependent variables $Y_{1}, Y_{2}, Y_{3}$ and $Y_{4}$, respectively. Age, education and income and so forth were independent variables. Factors that affect participant bids for information attributes were analyzed with a Tobit model.

Table 3. Variable definition and assignment.

\begin{tabular}{|c|c|c|}
\hline Variable & Definition & Expected Direction \\
\hline Bid for type I safety information $\left(\mathrm{Y}_{1}\right)$ & $\begin{array}{l}\text { Continuous variable; the final WTP price (that is } \\
\text { maximum WTP) gained from the MPL. }\end{array}$ & - \\
\hline Bid for type II safety information $\left(\mathrm{Y}_{2}\right)$ & $\begin{array}{l}\text { Continuous variable; the final WTP price (that is } \\
\text { maximum WTP) gained from the MPL. }\end{array}$ & - \\
\hline Bid for type III safety information $\left(\mathrm{Y}_{3}\right)$ & $\begin{array}{l}\text { Continuous variable; the final WTP price (that is } \\
\text { maximum WTP) gained from the MPL. }\end{array}$ & - \\
\hline Bid for type IV safety information $\left(\mathrm{Y}_{4}\right)$ & $\begin{array}{l}\text { Continuous variable; the final WTP price (that is } \\
\text { maximum WTP) gained from the MPL. }\end{array}$ & - \\
\hline Low age $\left(\mathrm{X}_{1}\right)$ & $\begin{array}{l}\text { Dummy variable; } 40 \text { years of age or younger }=1 \text {, } \\
\text { otherwise }=0\end{array}$ & + \\
\hline High age $\left(X_{2}\right)$ & $\begin{array}{l}\text { Dummy variable; } 60 \text { years of age or older }=1 \text {, } \\
\text { otherwise }=0\end{array}$ & - \\
\hline Low education $\left(\mathrm{X}_{3}\right)$ & $\begin{array}{l}\text { Dummy variable; junior high school and lower } \\
\text { education }=1 \text {, otherwise }=0\end{array}$ & - \\
\hline High education $\left(\mathrm{X}_{4}\right)$ & $\begin{array}{l}\text { Dummy variable; university and higher } \\
\text { education }=1 \text {, otherwise }=0\end{array}$ & + \\
\hline Low income $\left(X_{5}\right)$ & $\begin{array}{l}\text { Dummy variable; monthly income of } 2000 \text { yuan } \\
\text { and less = } 1 \text {, otherwise = } 0\end{array}$ & - \\
\hline High income $\left(\mathrm{X}_{6}\right)$ & $\begin{array}{l}\text { Dummy variable; monthly income of } 8000 \text { yuan } \\
\text { and more }=1 \text {, otherwise }=0\end{array}$ & + \\
\hline $\begin{array}{l}\text { History of foodborne disease due to } \\
\text { consumption of unsafe pork }\left(X_{7}\right)\end{array}$ & Dummy variable; yes $=1$, no $=0$ & + \\
\hline Perceived harm caused by unsafe pork $\left(X_{8}\right)$ & $\begin{array}{l}\text { Very great }=1 ; \text { great }=2 ; \text { moderate }=3 ; \text { small }=4 ; \\
\text { no harm }=5\end{array}$ & + \\
\hline Concern about food safety $\left(\mathrm{X}_{9}\right)$ & $\begin{array}{l}\text { Very concerned }=1 ; \text { somewhat concerned }=2 ; \\
\text { moderately concerned }=3 ; \text { not very concerned }= \\
4 ; \text { not concerned at all }=5\end{array}$ & + \\
\hline Satisfaction with food safety $\left(\mathrm{X}_{10}\right)$ & $\begin{array}{l}\text { A score of } 0 \text { to } 10 \text { was assigned according to the } \\
\text { level of satisfaction }\end{array}$ & - \\
\hline Confidence in food safety labeling $\left(\mathrm{X}_{11}\right)$ & $\begin{array}{l}\text { Highly confident }=1 \text {; fairly confident }=2 ; \\
\text { moderately confident }=3 \text {; not very confident }=4 ; \\
\text { not confident at all }=5\end{array}$ & + \\
\hline
\end{tabular}

\subsection{Results and Discussion}

As shown in Table 4, Prob > chi2 $=0.0000$, significances indicate that the overall fit of the Tobit model is good. Further findings are presented below. Participants' WTP for attributes of pork quality inspection, supply chain and supply chain-and-internal traceability was significantly affected by age. Participants over 60 years of age reported a significantly lower WTP for attribute of pork quality inspection compared with those under 60 years of age. Participants under 30 years of age reported a significantly higher WTP for attributes of supply chain and supply chain-and-internal traceability compared with those over 30 years of age. This coincides with the findings of Lim et al. [16], Wu et al. [7] and Lu et al. [30]. 
Table 4. Tobit regression results for the different information attributes.

\begin{tabular}{|c|c|c|c|c|}
\hline \multirow{2}{*}{ Independent Variable } & \multicolumn{4}{|c|}{ Dependent Variable } \\
\hline & Type $\mathbf{I}^{1}$ & Type II ${ }^{2}$ & Type III $^{3}$ & Type IV ${ }^{4}$ \\
\hline Low age & $0.019(0.259)$ & $0.175(0.255)$ & $0.442 * *(0.207)$ & $0.465^{* *}(0.234)$ \\
\hline High age & $-0.786^{* * *}(0.299)$ & $-0.355(0.296)$ & $-0.210(0.240)$ & $0.069(0.271)$ \\
\hline Low education & $-0.523 * *(0.260)$ & $-0.593 * *(0.256)$ & $-0.894^{* * *}(0.207)$ & $-0.892 * * *(0.234)$ \\
\hline High education & $2.169 * * *(0.262)$ & $1.637 * * *(0.258)$ & $0.774^{* * *}(0.209)$ & $0.966^{* * *}(0.237)$ \\
\hline Low income & $-1.170^{* * *}(0.380)$ & $-1.159^{* * *}(0.377)$ & $-0.943^{* * *}(0.305)$ & $-1.083^{* * *}(0.344)$ \\
\hline High income & $0.499 * *(0.228)$ & $0.566 * *(0.225)$ & $0.540^{* * *}(0.182)$ & $0.744^{* * *}(0.206)$ \\
\hline $\begin{array}{l}\text { History of foodborne disease due to } \\
\text { consumption of unsafe pork }\end{array}$ & $0.046(0.218)$ & $-0.404 *(0.214)$ & $-0.213(0.174)$ & $-0.217(0.196)$ \\
\hline Perceived harm caused by unsafe pork & $-0.267(0.167)$ & $-0.167(0.165)$ & $-0.185(0.134)$ & $-0.230(0.151)$ \\
\hline Concern about food safety & $-0.023(0.126)$ & $0.390^{* * *}(0.124)$ & $0.164(0.101)$ & $0.123(0.114)$ \\
\hline Satisfaction with food safety & $0.074(0.047)$ & $0.092 * *(0.046)$ & $0.113^{* * *}(0.038)$ & $0.094^{* *}(0.043)$ \\
\hline Confidence in food safety labeling & $-0.063(0.126)$ & $-0.190(0.124)$ & $0.306^{* * *}(0.101)$ & $0.113(0.114)$ \\
\hline Constant term & $3.675^{* * *}(0.722)$ & $1.408^{* *}(0.710)$ & $1.497^{* *}(0.577)$ & $2.370^{* * *}(0.652)$ \\
\hline
\end{tabular}

Education and individual monthly income had a significant influence on the participants' WTP for the four attributes. A negative impact was noticed in low-income and low-education participants and a positive one was noticed in high-income and high-education participants. This is because participants with higher education levels may have more correct cognition of pork safety $[16,23]$ and therefore may be more willing to pay a premium price for safety information. The result that income influenced the participants' WTP is consistent with the conclusions of Angulo and Gil [41], Sánchez et al. [42] and Liu et al. [43].

A history of foodborne disease due to the consumption of unsafe pork and participant concern about food safety had a significant impact on their WTP for quality management system certification. Participants having experience of foodborne disease and those who are more concerned about food safety are relatively less willing to pay premium for pork quality inspection attributes. This is contradictory to the findings of Lijenstolpe [44] and Schnettler et al. [45]. The main reason for this may be that those enterprises being disclosed in the series of pork safety events are mostly certified ones, thus leading consumers to directly question the trustworthiness of certification system. Participants' satisfaction with food safety had a significant positive impact on their WTP for quality management system certification, supply chain traceability and supply chain-and-internal traceability. However, it did not affect their WTP for pork quality inspection, which is inconsistent with the findings of Ubilava et al. [46]. A possible reason for this is that participants who were more satisfied with food safety had higher confidence in the government and enterprises [47] and thus were more willing to pay a premium for traceable pork information produced by enterprises certified for the quality management system. Additionally, such participants were more satisfied with routinely inspected pork and did not need additional pork quality inspection.

Participants' WTP for supply chain traceability was significantly positively affected by their confidence in food safety labeling. Reasonably, those who trust more in food safety labels would also recognize and trust traceability labels, especially when the labels contain key enterprise information.

Viewing the abovementioned statistics (Table 5), we found that the influencing factors for Participants' WTP for attributes of pork quality inspection are age, education and income. That is, participants over 60 years of age are 0.705 times less likely to pay than participants in the 60 s and below $(95 \% \mathrm{CI}$ : $-1.229 \sim-0.180$ ). The willingness to pay for high-educational participants above the university is 1.943 times higher than the willingness of participants below the university (95\% CI: 1.495 to 2.392 ). The willingness to pay for participants with low monthly income of 2000 yuan or less is 1.049 times lower than that of participants above 2000 yuan $(95 \%$ CI: $-1.713 \sim-0.384)$.

Those factors that affect Participants' WTP for attributes of quality management system certification most are education, income and food safety satisfaction. That is, the willingness to pay for junior high school and below is 0.503 times lower than that of participants above junior high 
school (95\% CI: $-0.927 \sim-0.078)$. The willingness of higher education participants above the university to pay is lower than the willingness of the participants below the university. Increase by 1.390 times (95\% CI: 0.968 1.810). The willingness to pay for participants with low monthly income of 2000 yuan or less is 0.983 times lower than the willingness to pay for participants above 2000 yuan $(95 \% \mathrm{CI}$ : $-1.609 \sim-0.357)$. Participants with high food safety satisfaction were 0.780 times more likely to pay than those with lower food safety satisfaction (95\% CI: 0.001 -0.155).

Those that affect the Participants' WTP for attributes of supply chain traceability most are education and income. That is, the factors affecting the participants' willingness to pay for the traceability of the supply chain are education and income, that is, the willingness to pay for the junior high school and below is 0.798 times lower than the willingness of the participants above the junior high school $(95 \%$ CI: $-1.157 \sim-0.439$ ), the willingness to pay for high-educational participants above the university is 0.691 times higher than the willingness of participants below the university (95\% CI: 0.326 1.056). The willingness to pay for participants with low monthly income of 2000 yuan or less is 0.842 times lower than that of participants above 2000 yuan (95\% CI: $-1.375 \sim-0.310)$.

Those that affect the Participants' WTP for attributes of supply chain-and-internal traceability most are education and income. That is, The factors affecting the supply chain-and-internal traceability attribute will be higher than the education and income, that is, the willingness to pay for the junior high school and below is 0.803 times lower than the willingness of the participants above the junior high school (95\% CI: $-1.213 \sim-0.394)$. The willingness to pay for high-educational participants above the university is 0.870 times higher than the willingness of participants below the university $(95 \%$ CI: $0.454 \sim 1.286)$. The willingness to pay for participants with low monthly income of 2000 yuan or less was 0.975 times lower than the willingness to pay for participants above 2000 yuan $(95 \% \mathrm{CI}$ : $-1.581 \sim-0.369)$. Participants in the high-month income of more than 8000 yuan will pay 0.670 times more than the willingness to pay for participants below 8000 yuan (95\% CI: 0.309 1.031).

Table 5. Marginal utility of the factors affecting consumers' WTP for the different information attributes.

\begin{tabular}{ccccc}
\hline Independent Variable & \multicolumn{4}{c}{ Dependent Variable } \\
\cline { 2 - 5 } & dy/dx (Type I) & dy/dx (Type II) & dy/dx (Type III) & dy/dx (Type IV) \\
\hline Low age & 0.017 & 0.149 & $0.395^{* *}$ & $0.419^{* *}$ \\
High age & $-0.705^{* * *}$ & -0.302 & $-0.187^{* *}$ & $0.062^{* *}$ \\
Low education & $-0.469^{* *}$ & $-0.503^{* *}$ & $-0.798^{* * *}$ & $-0.803^{* * *}$ \\
High education & $1.943^{* * *}$ & $1.390^{* * *}$ & $0.691^{* * *}$ & $0.870^{* * *}$ \\
Low income & $-1.049^{* * *}$ & $-0.983^{* * *}$ & $-0.842^{* * *}$ & $-0.975^{* * *}$ \\
High income & $0.448^{* *}$ & $0.480^{* *}$ & $0.482^{* * *}$ & $0.670^{* * *}$ \\
History of foodborne disease due to & 0.041 & $-0.343^{*}$ & -0.190 & -0.195 \\
consumption of unsafe pork & -0.239 & $-0.142^{*}$ & -0.165 & -0.207 \\
Perceived harm caused by unsafe pork & -0.021 & $0.331^{* * *}$ & $0.147^{* *}$ & $0.111^{* *}$ \\
Concern about food safety & 0.066 & $0.780^{* *}$ & $0.101^{* * *}$ & $0.085^{* *}$ \\
Satisfaction with food safety & -0.056 & $-0.161^{* * *}$ & $0.273^{* * *}$ & 0.102 \\
Confidence in food safety labeling & $3.891^{* * *}$ & $3.144^{* *}$ & $2.937^{* *}$ & $3.363^{* * *}$ \\
Constant term & &
\end{tabular}

\section{Main Conclusions and Policy Implications}

Based on the major risks in the Chinese pork supply chain system, this paper sets up four types of safety information attributes, namely: pork quality inspection, quality management system certification, supply chain traceability and supply chain-and-internal traceability for traceable pork hindquarters information. The major conclusions follow. Firstly, consumers are willing to pay a premium for food safety information attributes. Consumers had a higher WTP for information attributes with ex-ante quality assurance than for those with ex-post traceability. Thereinto, consumers were most willing to pay for the information attributes of pork quality inspection.

Secondly, heterogeneity was observed in consumer preferences for the different attributes of traceable pork information. High-income and well educated participants were willing to pay a premium for attributes with pork safety information, while young consumers and consumers with 
higher confidence in food safety labeling paid more attention to information attributes with ex-post traceability. However, consumers who were less concerned about food safety and had a history of foodborne disease were unwilling to pay a premium for quality management system certification.

This paper has reference value for governments to improve the consumption policy of the market of foods with profile information traceability. Firstly, it is workable to incorporate pork quality inspection information attributes at the initial stage of market development of pork with information traceability. There has not been any ex-ante quality information attributes in current pork markets in China. Therefore, the government should encourage pork producers (with rewarding mechanisms such as tax deduction or technological subsidy) to offer profile-traceable pork with ex-ante quality information attributes to the market. Secondly, based on the finding that consumers' preferences for profile-traceable pork are differentiated, the government should encourage producers to offer profile-traceable pork with different information attribute portfolios to meet the demands of different groups of consumers. This could also help expand the profile-traceable pork markets and increase the markets' quality level and thus lead to pork market sustainability.

This study has limitations that may imply future research directions. Our sample size was small in comparison to other kinds of experiment-based study. The BDM experimental method is complex and difficult to organize and it is difficult to recruit participants. Related to this, our experiments were conducted in just one (though representative) city in China. Future research should consider expanding to investigated areas to improve generalizability. This current study's pioneering efforts have implications for future studies that are interested in such consumer-related topics. Moreover, animal welfare information and place-of-origin certification are two more important forms of ex-ante quality information which could be considered by future studies to expand the types of information investigated.

Author Contributions: B.H. is the major writer for the first draft. L.W. led the project, conceptualized the paper and designed the tests; X.C. and R.Y. were major co-writers for the first draft. D.Z. sorted and logically analyzed the data; F.-S.T. reviewed and validated the manuscript and was in charge of the revision and resubmission.

Funding: We acknowledge the partial supports from the National Social Science Foundation of China under Grant [17CGL044].

Conflicts of Interest: The authors declare no conflict of interest.

\section{References}

1. Aung, M.M.; Chang, Y.S. Traceability in a food supply chain: Safety and quality perspectives. Food Control 2014, 39, 172-184. [CrossRef]

2. Kher, S.V.; Frewer, L.J.; Jonge, J.D.; Wentholt, M.; Davies, O.H.; Luijckx, N.B.L. Experts' perspectives on the implementation of traceability in Europe. Br. Food J. 2010, 112, 261-274. [CrossRef]

3. Sterling, B.; Gooch, M.; Dent, B.; Marenick, N.; Miller, A.; Sylvia, G. Assessing the Value and Role of Seafood Traceability from an Entire Value-Chain Perspective. Compr. Rev. Food Sci. Food Saf. 2015, 3, 205-243. [CrossRef]

4. Pizzuti, T.; Mirabelli, G. The Global Track \&Trace System for food: General framework and functioning principle. J. Food Eng. 2015, 159, 16-35.

5. Hobbs, J.E.; Bailey, D.V.; Dickinson, D.L. Traceability in the Canadian Red Meat Sector: Do Consumers Care. Can. J. Agric. Econ. 2005, 1, 47-65. [CrossRef]

6. Wu, L.H.; Wang, S.X.; Xu, L.L. Consumer demand for traceable food: The case of traceable pork. J. Public Manag. 2013, 3, 119-128. (In Chinese)

7. Wu, L.H.; Wang, S.X.; Zhu, D.; Hu, W.Y.; Wang, H.S. Chinese consumers' preferences and willingness to pay for traceable food quality and safety attributes: The case of pork. China Econ. Rev. 2015, 35, 121-136. [CrossRef]

8. Ortega, D.L.; Wang, H.H.; Widmar, N.J.O. Welfare and Market Impacts of Food Safety Measures in China: Results from Urban Consumers' Valuation of Product Attributes. J. Integr. Agric. 2014, 6, 1404-1411. [CrossRef] 
9. Lancaster, K.J. A New Approach to Consumer Theory. J. Political Econ. 1966, 6, 132-157. [CrossRef]

10. Nelson, P. Advertising as Information. J. Political Econ. 1974, 3, 311-329. [CrossRef]

11. Hobbs, J.E. Information asymmetry and the role of traceability systems. Agribusiness 2004, 4, $397-415$. [CrossRef]

12. Wu, L.H.; Wang, H.S.; Zhu, D. Analysis of consumer demand for traceable pork in China based on a real choice experiment. China Agric. Econ. Rev. 2015, 2, 303-321. [CrossRef]

13. Hobbs, J.E.; Sanderson, K.; Haghiri, M. Evaluating willingness-to-pay for bison attributes: An experimental auction approach. Can. J. Agric. Econ. 2006, 2, 269-287. [CrossRef]

14. Verbeke, W.; Ward, R.W. Consumer interest in information cues denoting quality, traceability and origin: An application of ordered probit models to beef labels. Food Qual. Prefer. 2006, 6, 453-467. [CrossRef]

15. Loureiro, M.L.; Umberger, W.J. A choice experiment model for beef: What US consumer responses tell us about relative preferences for food safety, country-of-origin labeling and traceability. Food Policy 2007, 4, 496-514. [CrossRef]

16. Lim, K.H.; Hu, W.Y.; Maynard, L.J.; Goddard, E.U.S. Consumers' Preference and Willingness to Pay for Country-of-Origin-Labeled Beef Steak and Food Safety Enhancements. Can. J. Agric. Econ. 2013, 61, 93-118. [CrossRef]

17. Lusk, J.L.; Feldkamp, T.; Schroeder, T.C. Experimental auction procedure: Impact on valuation of quality differentiated goods. Am. J. Agric. Econ. 2004, 2, 389-405. [CrossRef]

18. Xue, H.; Mainville, D.; You, W.; Nayga, R.M., Jr. Consumer preferences and willingness to pay for grass-fed beef: Empirical evidence from in-store experiments. Food Qual. Prefer. 2010, 7, 857-866. [CrossRef]

19. Zhang, C.; Bai, J.; Wahl, T.I. Consumers' willingness to pay for traceable pork, milk, and cooking oil in Nanjing, China. Food Control 2012, 1, 21-28. [CrossRef]

20. Bai, J.; Zhang, C.; Jiang, J. The role of certificate issuer on consumers' willingness to pay for milk traceability in China. Agric. Econ. 2013, 4-5, 537-544. [CrossRef]

21. Haghiri, M. An evaluation of consumers' preferences for certified farmed Atlantic salmon. Br. Food J. 2014, 7, 1092-1105. [CrossRef]

22. Lombardi, A.; Vecchio, R.; Borrello, M.; Caracciolo, F.; Cembalo, L. Willingness to pay for insect-based food: The role of information and carrier. Food Qual. Prefer. 2019, 72, 177-187. [CrossRef]

23. Jin, S.S.; Zhou, L. Consumer interest in information provided by food traceability systems in Japan. Food Qual. Prefer. 2014, 36, 144-152. [CrossRef]

24. Wu, L.H.; Wang, H.S.; Liu, X.L. Traceable pork: Information combination and consumers' wiliness to pay. China Popul. Resour. Environ. 2014, 4, 35-45. (In Chinese)

25. De-Magistris, T.; Gracia, A.; Nayga, R.M., Jr. On the use of honesty priming tasks to mitigate hypothetical bias in choice experiments. Am. J. Agric. Econ. 2013, 5, 1136-1154. [CrossRef]

26. Unnevehr, L.; Eales, J.; Jensen, H. Food and Consumer Economic. Am. J. Agric. Econ. 2009, 2, 506-521. [CrossRef]

27. Wu, L.H.; Qin, S.S.; Zhu, D.; Li, Q.G.; Hu, W.Y. Consumer preferences for origin and traceability information of traceable pork. Chin. Rural Econ. 2016, 6, 47-62. (In Chinese)

28. Reid, L.M.; O'Donnell, C.P.; Downey, G. Recent technological advances for the determination of food authenticity. Trends Food Sci. Technol. 2006, 17, 344-353. [CrossRef]

29. Akaichi, F.; Gil, G.M.; Nayga, R.M. Assessing the market potential for a local food product Evidence from a non-hypothetical economic experiment. Br. Food J. 2012, 1, 19-39. [CrossRef]

30. Lu, J.; Wu, L.H.; Wang, S.X. Consumer preference and demand for traceable food attributes. Br. Food J. 2016, 9, 2140-2156. [CrossRef]

31. Alphonce, R.; Alfnes, F. Eliciting Consumer WTP for Food Characteristics in a Developing Context: Application of Four Valuation Methods in an African Market. J. Agric. Econ. 2017, 1, 123-142. [CrossRef]

32. Akaichi, F.; Nayga, R.M., Jr.; Gil, G.M. Assessing Consumers' Willingness to Pay for Different Units of Organic Milk: Evidence from Multiunit Auctions. Can. J. Agric. Sci. 2012, 4, 469-494. [CrossRef]

33. Hamukwala, P.; Oparinde, A.; Binswanger-Mkhize, H.P. Design Factors Influencing Willingness-to-Pay Estimates in the Becker-DeGroot-Marschak (BDM) Mechanism and the Non-hypothetical Choice Experiment: A Case of Biofortified Maize in Zambia. J. Agric. Resour. Econ. 2019, 1, 81-100. [CrossRef] 
34. Ginon, E.C.; Chabanet, P.; Combris, S.I. Are decisions in a real choice experiment consistent with reservation prices elicited with BDM 'auction'? The case of French baguettes. Food Qual. Pref. 2014, 31, 173-180. [CrossRef]

35. Drichoutis, A.C.; Lusk, J.L. What can multiple price lists really tell us about risk preferences? J. Risk Uncertain 2016, 53, 89-106. [CrossRef]

36. Tamas Csermely, T.; Rabas, A. How to reveal people's preferences: Comparing time consistency and predictive power of multiple price list risk elicitation methods. J. Risk Uncertain 2016, 53, 107-136. [CrossRef] [PubMed]

37. Becker, G.M.; Degrooot, M.H.; Marschak, J. Measuring utility by a single response sequential method. Behav. Sci. 1964, 3, 226-232. [CrossRef]

38. Ginon, E.P.; Combris, Y.; Lohéac, G.; Enderli, S.I. What do we learn from comparing hedonic scores and willingness-to-pay data? Food Qual. Prefer. 2014, 33, 54-63. [CrossRef]

39. Gao, Z. Research on Retailer Dynamic Pricing and Procurement Strategy Based on Customer's Willingness to Pay. Master's Thesis, Tsinghua University, Beijing, China, 2011.

40. Wu, L.H.; Xu, L.L.; Zhu, D.; Wang, X.L. Factors affecting consumer willingness to pay for certified traceable food in jiangsu province of china. Can. J. Agric. Econ. 2012, 3, 317-333. [CrossRef]

41. Angulo, A.M.; Gil, J.M. Risk perception and consumer willingness to pay for certified beef in Spain. Food Qual. Prefer. 2007, 8, 1106-1117. [CrossRef]

42. Sánchez, M.; Beriain, M.J.; Carr, T.R. Socio-economic factors affecting consumer behaviour for United States and Spanish beef under different information scenarios. Food Qual. Prefer. 2012, 24, 30-39. [CrossRef]

43. Liu, X.L.; Xu, L.L.; Zhu, D.; Wu, L.H. Consumers' WTP for certified traceable tea in China. Br. Food J. 2015, 5, 1440-1452. [CrossRef]

44. Lijenstolpe, C. Evaluating animal welfare with choice experiments: An application to Swedish pig production. Agribusiness 2008, 1, 67-84. [CrossRef]

45. Schnettler, B.; Vidal, R.; Silva, R.; Vallejos, L.; Sepulveda, N. Consumer willingness to pay for beef meat in a developing country: The effect of information regarding country of origin, price and animal handling prior to slaughter. Food Qual. Prefer. 2009, 20, 156-165. [CrossRef]

46. Ubilava, D.; Foster, K.A.; Lusk, J.L.; Nilsson, T. Effects of income and social awareness on consumer WTP for social product attributes. Technol. Forecast. Soc. Chang. 2010, 4, 587-593. [CrossRef]

47. Wang, L.; Huo, X. Willingness-to-pay price premiums for certified fruits-A case of fresh apples in China. Food Control 2016, 64, 240-246. [CrossRef]

(C) 2019 by the authors. Licensee MDPI, Basel, Switzerland. This article is an open access article distributed under the terms and conditions of the Creative Commons Attribution (CC BY) license (http:/ / creativecommons.org/licenses/by/4.0/). 